\title{
Stop smoking the Easyway: addiction, self-help and tobacco cessation
}

Donncha Marron

This is the author's version of an article accepted for publication in Contemporary Drug Problems. The published version will be available from:

https://journals.sagepub.com

Reprinted by permission of SAGE Publications.

The article is protected by copyright. Users may download and save a local copy of an article accessed in an institutional repository for the user's personal reference. For permission to reuse an article, please follow the publisher's Process for Requesting Permission available from: https://uk.sagepub.com/engb/eur/process-for-requesting-permission . 


\title{
Stop Smoking the Easyway: Addiction, Self-Help and Tobacco Cessation
}

\author{
Abstract \\ This article examines Easyway, a popular clinical and self-help method for the treatment of \\ smoking addiction established by the late Allen Carr in 1984. It begins by addressing how \\ smoking has come to be constituted as a neuropharmacological addiction and some of the \\ issues and concerns raised against this in the social sciences. After situating its theoretical \\ and empirical focus, the article then proceeds with an interpretative thematic analysis of a \\ selection of Easyway self-help texts. The aims here are as follows: firstly, to show how \\ Easyway, as a discourse, constitutes the problem of nicotine addiction in novel and distinctive \\ ways; secondly, to elaborate how the Easyway texts seek to govern readers - paradoxically, \\ through their free capacity for reflection, introspection and action - to overcome their situated \\ addiction to smoking; and thirdly, to identify and locate the significance of the author's \\ implicit claims to charisma in underpinning his authority to know and treat nicotine \\ addiction.
}

\section{Keywords}

addiction, sociology, tobacco, self-help, smoking, textual analysis

\section{Introduction}

Allen Carr was a prominent international figure in the field of tobacco cessation before his death from lung cancer in 2005. Born in 1934, his autobiography describes his path from working-class childhood in Putney, London to leadership of the global Easyway stopsmoking conglomerate he founded (Carr, 2004). Benefiting from a selective but state-funded grammar school education, he can, perhaps, be seen as coming of age as part of an upwardly 
mobile and aspirational working-class generation in postwar Britain (Themelis, 2008). While not particularly studious, he exhibited drive and ambition, firstly at youth sports and later in training and qualifying as a chartered accountant. In the latter, however, he was possessed with little apparent enthusiasm for either the profession or the world of business and finance.

A smoker from his teenage years, Carr's autobiography recounts an intensifying, debilitating feeling of dependency on cigarettes. He witnessed his smoker father die of lung cancer, but failed himself on numerous occasions to quit or even curtail his own tobacco consumption which peaked at 100 cigarettes a day. However, in his late 40s, he experienced a breakthrough composed of two separate, seemingly mundane realisations: firstly, that smoking is an 'addiction', and secondly, that physical withdrawal from nicotine creates subjective feeling of anxiety and stress that the smoker relieves through further nicotine consumption. Together, in his mind, these proved revelatory and he immediately stopped smoking, a process he not only found straightforward but pleasurable. Overjoyed at his new freedom from tobacco and electrified by the thought he had discovered something revolutionary, he set out on a new career to 'cure the world of smoking', establishing his first clinic under the Easyway brand in London in 1984.

What is particularly striking about Easyway is precisely its declared easiness. It offers the possibility that any smoker can quit, simply and easily: without weight gain or cravings, without nicotine patches or gum, and without the exercise of willpower. The only requirement is that smokers absorb its message and follow the instructions. These are extraordinary assertions considering the success rate for cessation with the British NHS Stop Smoking Service is around 14\% after 12 months (Brose et al, 2012) while the addictive properties of nicotine have been compared to heroin (ASH Scotland, 2013). However, it has 
recently claimed some scientific evidence for its efficacy. On the basis of a randomized control trial in Ireland, Keogan et al. (2018) found significantly higher quit rates up to 12 months for Easyway clinic clients compared to participants in the state-backed smoking cessation service Quit.

Easyway currently operates clinics in over 50 countries around the world where trained practitioners offer one-off individual and group therapy sessions to participants (Easyway, 2017). The Easyway method is also available to smokers in the form of a self-help book, The Easy Way to Stop Smoking. First published in 1985, the book has sold 15 million copies, been translated into 38 languages, and was followed by other titles including The Only Way to Stop Smoking Permanently and How to Stop Your Child Smoking. Carr also adapted the Easyway method for other addictions like alcohol and overeating while, most recently, Easyway has branched into new areas of problematic consumption including caffeine, sugar and vaping. The brand is an enduring one with a claimed 30 million people freed from addiction. Particularly striking in this regard are the number of celebrity endorsements with former smokers Richard Branson, Ashton Kutcher, Ellen DeGeneres and others all personally attesting to the method's effectiveness.

Within this article, I set out to investigate the Easyway method sociologically. I examine the historical framing of smoking as addictive and establish the empirical focus. I then proceed with a qualitative thematic analysis of a selection of Easyway self-help books. The purpose here is not to evaluate their effectiveness for readers or to deconstruct meaning in order to reveal a subterranean ideology at work; on the contrary, my purpose is to understand how Easyway constitutes the problem of nicotine addiction in novel ways and to appraise how it 
seeks to govern readers to overcome addiction. I also identify the importance of charisma in underpinning the author's claim to distinctive expertise within the field of smoking cessation.

\section{The Making of Nicotine Addiction}

Authorities have long expressed concern about the habituated character of smoking. Burnham (1993) for instance points to $19^{\text {th }}$ century accounts that condemned smoking as an immoral and unhealthy habit. At that century's end, along with other forms of conduct associated with working-class urban living, it became a target for regulation by concerned moral reformers (Goodman, 1992; Tate, 1999; Hughes, 2003). Henry Ford's (1914) famous invective against 'the little white slaver' drew, in passing, on anecdotal evidence that tobacco consumption could corrode the will of young boys, reducing them to a state of absolute dependence. However, as Hilton (2000) reveals, the British medical establishment were undecided about tobacco by the mid- $20^{\text {th }}$ century. Some researchers identified clearly the addictive properties of smoking, yet remained at the margins. In contrast, many articles in The Lancet medical journal pointed to smoking's beneficial effects on anxiety and stress and articulated a clear distinction between the effects of tobacco and other kinds of drugs (Hilton, 2000, pp. 181-2).

In Britain in the 1970s, against rising concerns about its health consequences and apparent difficulties for some in quitting, some medical authorities problematized smoking as a form of dependence driven, in the main, by psychological disposition (Berridge, 2013). However, in the 1990s, nicotine addiction became the dominant framework of explanation, driven by institutional realignments in public health promotion and the new potency of neuroscientific explanation drawn from research in the United States (Berridge, 2007, 2013; Rooke, 2013). Stubbornly high rates of smoking, particularly in lower class groups and among young 
women, and a new approach to harm reduction, justified a public health strategy of using nicotine replacement therapy as a critical tool in primary care to aid cessation.

Within the current hegemonic framework of neuropharmacology, the cigarette is a highly engineered device for the speedy delivery of nicotine to the brain (Benowitz, 2010; NIDA 2018). There, the nicotine molecules bind with receptors causing the release of neurotransmitters, in particular, dopamine, associated with feelings of pleasure and anticipation; in turn, its rapid dissipation encourages re-dosing behaviour by smokers to maintain these same reward effects. Over time, repeated exposure induces tolerance as brain receptors become unresponsive; however, during periods of non-exposure they become responsive again, producing characteristic feelings of craving and withdrawal. The production of increased levels of corticotropin-releasing factor, in turn, amplifies withdrawal through inducing feelings of stress. Together, these foment subjective experiences of irritability and depression. Ongoing exposure to nicotine is also implicated in changes in brain functions associated with learning, memory and self-control with consequential effects on smoker behaviour.

This conceptualization of the smoker as a 'neurochemical self' (Rose, 2003) whose normal brain chemistry has become 'hijacked' has been used in attempts to destigmatise addiction (Campbell, 2010). Rather than a weakness of the will, many researchers in the field have attempted to portray it as a somatic disease over which the individual has limited agency and which should be treated medically, ideally through pharmacological targeting of the brain's neurochemistry. It has also led to some degree of conflation of different forms of addiction into one generalized condition - 'chronic, relapsing brain disease' - with a strong genetic component (Fraser et al, 2014). 
There are, however, problems with this paradigm. At the level of research, the desire to grant nicotine addiction a disease aetiology runs up against the problem that no clear biological markers specifically identify it (Hammer et al, 2013). In consequence, despite advances in neuroimaging that 'show' addiction in the brain, diagnosis remains dependent on criteria of behaviour self-reported by smokers (Fraser et al, 2014, pp. 33-7). At the same time, notwithstanding attempts (with limited success) to create pharmacological remedies that act directly on neural pathways to inoculate against addiction, treatment continues to focus on strategies of behavioural change (Dingel et al, 2012; Elam, 2015). Therefore, it is not entirely clear that 'molecularizing' addiction actually de-stigmatizes it as an illness outside the scope of moral responsibility (Coonfield, 2008). Certainly, public attitudes, while accepting of the premise of nicotine addiction, are somewhat sceptical of its framing as a disease and continue to adhere to the value of personal responsibility in dealing with it (Brandt, 2007; Morphett et al, 2017).

Critical social constructionist perspectives contest the ontological reality of addiction as a discoverable disease. Instead, their focus turns to the social processes underpinning the diagnosis of behaviour and people in terms of addiction. Within some of these accounts, the 'discovery' of addiction is a function of the emergence of liberalism and its emphasis on the freedom of the subject (Coonfield, 2008; Reith, 2004, 2019; Sedgwick, 1992; Valverde, 1996, 1997). In this context, the addict is a persistent, if unstable, moral-medical identification of those deemed incapable of regulating desire under political conditions that privilege individual autonomy and freedom. Arguably, then, a further direct relationship underlies the rise of neoliberal discourses in the latter half of the $20^{\text {th }}$ century that advocate consumer freedom and the expansion of addiction, over the same time period, into seemingly 
limitless categories of consumption. In consequence, the ideal of the identity-crafting, selfgoverning free consumer faces its nemesis in the spectre of the addict whose compulsive, self-destructive consumption offers little pleasure, purpose or meaning (Cohen, 2000; Duff, 2015; O’Malley and Valverde, 2004).

These accounts, to some extent, run the risk of trivializing the debilitating experiences of individuals who do struggle with substance use. As such, they are disinclined to examine how social and cultural processes shape visceral feelings and impulses to consume experienced as emanating, unchosen, from within the self (Weinberg, 2002, 2013). These accounts might also be accused of over-determining subject positions and ignoring the ways in which individuals actively interpret, negotiate, adapt and resist the meanings of labels like 'addict' (Triandafilidis et al, 2018) and 'smoker' (Denscombe, 2010; Nachtigal and Kidron, 2015). Furthermore, they elide the complexity and specificity of the ways in which addiction itself is produced. While medical authorities might attempt to signify nicotine consumption as brain pathology, in reality, such dichotomies of normality and abnormality are highly unstable in practice (Keane, 2002). Nicotine does not produce a high, usage tends to be stable and withdrawal does not provoke severe physical reaction. Meanwhile, general cultural and social responses, while increasingly limiting and stigmatizing of smoking, have not yet graduated to formal legal prohibition in the manner of other narcotics (Acker, 2002, pp. 219-20).

The precise meaning and content of addiction discourses become apparent only when individuals, authorities and groups problematize consumption and propose particular techniques for thinking about, and acting upon, the problematic consuming subject (Reinarman, 2005; Coonfield, 2008; McCoy, 2010). In this regard, biomedical accounts, while hegemonic, do not operate alone. For instance, in their analysis of Alcoholics 
Anonymous, Valverde and White-Mair (1999) argue this enduringly successful organization adapts medicalized notions of addiction, reconfiguring and infusing them with ethical meanings that go beyond a concern for alcohol. The distinctive philosophy and everyday practice of the movement gives this expression as its members pragmatically 'work' the twelve steps programme. In ongoing fellowship with other addicts, with a learned vocabulary and secured by values of anonymity and non-judgementalism, one talks about one's experiences of addiction and, in turn, listens to others. One takes responsibility for the consequences of one's addiction but assumes a state of powerlessness over it, seeking strength instead in a 'higher power'. Through the group, individually and collectively, a state of recovery from alcoholism is sought - not a cure but a daily, recursive reconciliation.

\section{Empirical focus and method}

The previous section drew attention to how the problem of addiction is contested and how specific constitutions of addiction serve as means to problematize and govern the conduct of particular individuals and groups in particular ways. The empirical focus of this article, then, seeks to apply this by examining the distinctive framing of smoking as addiction within a number of Easyway self-help books authored by Allen Carr and how, through this framing, readers, as addicted smokers, are governed towards cessation. Unsurprisingly, there are many self-help texts on smoking cessation; some are more generically therapeutic in nature while others are organized about particular interventions such as cognitive behavioural therapy (e.g. Pemberton, 2015) or hypnosis (e.g. McKenna, 2007). However, Allen Carr's texts are, by far, the most influential. For example, at the time of writing, overall Amazon sales rankings locate Carr's Easyway to Stop Smoking at number 383 while its nearest rival, celebrity hypnotist Paul McKenna's Quit Smoking Today, is ranked at number 50,573. How, then, should we think about such self-help books as a social phenomenon? 
In Giddens's (1991) conceptualization of late modernity, individual reflexivity - the capacity to engage with new knowledge and self-consciously feed it back into living one's life becomes a central preoccupation. With traditional practices effaced, individuals are increasingly free, and obligated, to establish meaningful self-identities for themselves. However, these conditions discredit the passive acceptance of authority. Instead, individuals must pick-and-choose from an array of ever-shifting lifestyle leaders to follow, governed through the logic of the market (Bauman, 2000). Within this process, Nikolas Rose (1996, 1999) has pointed to the significance of therapeutic discourse and practice. These are forms and applications of knowledge which originate in the 'psy-sciences' - psychiatry, psychology and psychotherapy - that are disseminated within other institutional spheres and circulate widely through systems of cultural production and consumption. In the act of consumption, the individual takes on a new responsibility for the self. They interrogate their biography, personal relationships and emotional states, deploy recommended tools for self-evaluation and self-scrutiny, and engage with the techniques endorsed by experts for working upon the goal of one's own happiness and contentment.

Sociological research on self-help books have drawn attention to their specific role as commodities, marketed to a mass readership as pragmatic and ethical solutions for a diverse array of everyday concerns for how one should live (Dolby 2005; McGee, 2007; Simmonds, 1992). To these ends, they are repositories of ideas, directions and prompts, often characterized by identifiable therapeutic codes and conventions (Illouz, 2008). Through reading, the text becomes a conduit through which the author, through laying claim to some form of expertise and insight, directs the individual to reflect upon the self, cognitively and emotionally. What is significant here is the emphasis on a personal or private self that one is 
tasked with having a relationship with, and an ethical obligation to (Hazleden, 2003). Within this vision, 'the self is ontologically separate from itself' and it is this link that self-help texts locate as the primary route of therapeutic change. The reader has lost sight of who they are and it becomes incumbent upon them to rediscover it. The self-help book, therefore, serves as an articulation of, and practical response to, self-recognized problems activated through the process of reading (Cherry, 2008).

The empirical sections of this article involve a thematic analysis of a selection of Easyway self-help books authored by Allen Carr. The purpose here is not to evaluate Easyway's effectiveness as a method of smoking cessation for readers, assess how readers interpret these messages or deconstruct the texts for hidden ideological meaning. Rather, the following three questions drive the enquiry:

1. What is the nature of smoking addiction constituted within the discourse of Easyway?

2. How does Easyway attempt to govern readers - by way of their free capacity for introspection, reflection and action - to overcome their nicotine addiction?

3. How does the author declare authority to help readers overcome addiction and what is the claimed nature of his expertise?

Three texts were chosen: The Easy Way to Stop Smoking (1985, $2^{\text {nd }}$ edition 1999]), The Only Way to Stop Smoking Permanently (1995) and Easy Way for Women to Stop Smoking Without Gaining Weight (2003). These are authored by Allen Carr and remain in print, representing a robust cross-section of the author's publications in the area. It should be noted that, since his death, similar books continue to be published under the Easyway brand, however, these were discounted as the research here is particularly interested in the role of this author. 
The books themselves are moderate in length with a large number of small, episodic chapters. Typical of the genre, the texts are written in accessible language and are characterized by an unadorned informal conversational style with no recourse to technical concepts or formal theories (Simmonds, 1992, p. 121). The author refers a number of times to central ideas and arguments which produce a sense of repetition common in self-help texts (Dolby, 2005, pp. 62-3). However, he explicitly acknowledges this, arguing that constant restatement of important points is necessary to counteract the 'brainwashing' he claims smokers suffer from. In terms of style, we can divide the texts into a number of different, often overlapping stylistic modes:

- Autobiography draws from the author's own life experiences before and after his discovery of Easyway.

- Analyses of smoking states and processes articulate the physical and psychological conditions of smokers, with liberal use of metaphors, parables and practical illustrations that explain the processes of addiction at work.

- Philosophical discussions address the particular nature of modern society, from the point of view of the author, and the wider cultural and political determinants that bear upon the experience of nicotine addiction.

- Instructions systematically guide the reader on the particular steps required to quit smoking successfully.

- Reflections comment on the method itself and its political positioning within the wider context of tobacco consumption and public health.

Due to the nature of the material and the focus of the questions, I chose thematic analysis as the method of analysis (Bryman, 2016, pp. 584-89; Seal, 2016). I digitized and uploaded the three texts to NVivo 11 to facilitate this process. During the first coding process, the text was 
read and labelled with discrete descriptive nodes that captured distinctive broad patterns of similarity and difference across the texts. In this primary phase, around 30 preliminary codes emerged from the data. Through an interrogation of the coding schema and further reflection on the emergent research questions, a second round of coding reduced and condensed the number of main codes down to 18 , along with a number of subsidiary codes. At this stage, the content of these codes was elaborated reflexively using the memo function in NVivo and their relative importance and interpretative meaning began to coalesce as well as their location within wider thematic areas. The final coding iteration established 12 main codes as stable categories, with most of these containing a number of more minor, subsidiary codes. The main coding set was then organized in relation to two major themes appropriate to the research questions.

\section{Constituting Addiction}

The first theme I address concerns how Easyway discursively produces the concept of addiction. Within this theme, three important categories are explored including 'experience', 'self-deception', and 'cultural origins'. This theme charts the ways in which smoking is situated and rationalized as a particular problem of compulsion located between the recursive act of smoking, the embodied and psychological state of smokers, and the wider cultural and social spaces that smokers inhabit.

\section{Experience}

The concept of addiction is central and constitutes the primary phenomenal experience for all smokers with the texts offering vivid descriptions of the existential and embodied suffering that addiction represents. On the one hand, smoking is typified as an endless and compulsive chain of cigarettes, with all the monetary, health and personal costs entailed. On the other 
hand, smoking is characterized as implacable trajectory. Addiction is expansive, moving from an occasional cigarette to a payload of whatever the smoker can endure, physically and financially. It is also a descent from health and wellbeing into degradation and death, from the first carefree puff as a teenager to the chain-smoking patient with a terminal cancer diagnosis (cf. Room, 2003, pp. 228-231). Through this compulsion to consume, one is, in turn, physically and mentally consumed. The key metaphor used here is the pitcher plant:

This is the real subtlety and strength of the nicotine trap, the greatest allies of the trap are the victims themselves. It is so designed to make the smoker think that they are not hooked and that, no matter what depth of degradation they have reached, they are smoking because they choose to smoke. They create their own imaginary pitcher plant and the deeper they sink into the abyss, the greater becomes their desire to remain trapped. (Carr, 1995, p. 101)

With every smoker, there is the original misstep, a first cigarette consumed usually in early adolescence. Surrounding this act is a tragic lack of awareness of the likely chain of addiction implicit in the first act (cf. Slovic, 2001). Here, cognitive reason is negatively juxtaposed with embodied reason; the young person believes that she can easily experiment with smoking before addiction sets in, not heeding their own physical disgust, still less the plaintive cry of the rhetorical older smoker that to smoke the second cigarette is already to be on the path of addiction.

In the Easyway framing, one smokes only because one is addicted to nicotine, the physiologically addictive substance contained within tobacco. However, physical dependence is within itself of negligible importance; the physical pangs are not painful, representing 
merely a physical sensation of emptiness similar to hunger. On the contrary, the primary experience of smoking addiction is taken to be a psychological - an inculcated state of fear of being denied the opportunity to smoke, of dread at the consequences of one's smoking, and anxiety that one cannot lead a happy life unless one can smoke. The texts also draw particular attention to the personal and social situations and contexts where the smoker feels acutely the need or desire to smoke. Addiction is not unvariegated or independent of the spaces and situations that smokers negotiate in everyday life (cf. Winkler et al, 2011). Such contexts are perceived in the mind of the smoker as unpleasurable or unmanageable without smoking: work, pub, driving, after a meal and so on. These represent key geographical, temporal and psychological sites that trigger a strong desire to smoke in the mind of the smoker and which must be confronted if they are to quit successfully.

\section{Self-Deception}

One of the key strategies of Easyway, as I will discuss below, is to harness the smoker's own capacity for reason. Here, the rational acting self is tasked with confronting the delusional addicted self. Delusions, in this sense, are presented as a set of commonly held defences that smokers rhetorically deploy towards others and themselves. They help smokers rationalize why they smoke and avoid confronting the discomforting reality of their own addicted state. However, these are not just private stories but widely believed cultural narratives, including:

- $\quad$ Pleasure. One enjoys the physical taste and embodied experience of smoking.

- Necessity. One needs to smoke to sustain oneself or to manage stress or boredom.

- Choice. One believes that one can quit at any time or that one's smoking is a choice.

- Propinquity. One wishes to quit but will do so at some future point. 
- Adversity. One is anxious that stopping smoking is difficult and that life would be impossible to manage without smoking.

In order to counter each of the delusions, the author deploys an array of logical arguments that reveal these delusions as fallacious. For example:

It usually takes us a long time to realize that we are hooked because we suffer from the illusion that smokers smoke because they enjoy a cigarette, not because they have to have a cigarette. While we are not enjoying them (which we never do), we suffer from the illusion that we can stop whenever we want to. (Carr, 1999, p. 60)

Observe smokers who are smoking because they are bored. They still looked bored. The cigarette doesn't relieve the boredom. As an ex-chain-smoker I can assure you that there are no more boring activities in life than lighting up one filthy cigarette after another, day in day out, year in year out. (Carr, 1999, p. 30)

The author calls out these delusions as brainwashing that prevents smokers from recognizing the true nature of smoking as nothing more, or less, than addiction. They require patient confrontation in order to undermine the smoker's belief that anything purposive or meaningful underlies the practice of smoking. On facing up to the delusions, breaking the addiction becomes both easy and liberating.

\section{Cultural Origins}

Addiction, however, is not merely a private trouble but also one that is culturally determined. In this, the author advances a quasi-Rousseauian worldview that juxtaposes naturalism and 
worldliness. Humans, along with other life, are beings perfect within themselves, either by godly design or evolution. We exercise a pre-rational, instinctive judgement in relation to our bodies which is reflected in the fact that we are physically repulsed by smoking in any first instance, our bodies instinctively recognizing nicotine for the poison that it is. However, human sociability and culture - whether teenage status anxiety, manipulative tobacco advertising or the decadent lure of 'cool' - encourages individuals to override this embodied knowledge. Worldliness subverts nature and individuals, in consequence, become ensnared in nicotine addiction. Smokers come to feel dependent upon nicotine, either for pleasure or simply to manage. However, our bodies are already bequeathed by nature to enjoy pleasure or deal with stress; smoking, rather than facilitating pleasure or stress management as smokers perceive, actually undermines them. In consequence, a desire to smoke is a perverse and inauthentic part of the individual's self.

\section{Governing Cessation}

The second theme from the analysis concerns Easyway's attempts to govern readers. This theme involves four main categories: 'the shepherd', 'the paradox of reason', 'false paths' and 'achieving redemption'. Taken together, these interlink the peculiar nature of the authority of the author and how the smoker is encouraged to rethink and confront the nature of the nicotine-addicted self.

\section{The Shepherd}

A critical element to the Easyway method is the figure of the author, Allen Carr. On the one hand, Carr claims authority through his ordinariness - his life experience as a heavy smoker for many years, his repeated attempts to quit and his continual failures to do so. Just as the reader has done, he himself smoked that first cigarette in adolescence, succumbed to heavy 
tobacco addiction in adulthood, bore the health and other costs of smoking through much of his life, and struggled to quit. He suffered and failed just as the reader has suffered and failed:

I had reached the stage where I knew it was killing me. I had a permanent headache with the pressure of the constant coughing. I could feel the continuous throbbing in the vein that runs vertically down the centre of my forehead, and I honestly believed that any moment there would be an explosion in my head and I would die from a brain haemorrhage. It bothered me, but it still didn't stop me. (Carr, 1999, p. 15)

At the same time, Carr's authority resides in an extraordinary epiphany, an ineffable and mysterious moment in his past. He underwent hypnosis to treat his smoking; although a failure he followed this by reading some extracts of a medical textbook describing the relatively banal physical symptoms of nicotine addiction. In one moment, he was gripped by a sudden, wonderful certainty: that he did not need to smoke and that he would never need to smoke again:

When the fog is lifted from your eyes, it is like awakening from a permanent nightmare. I was released from a black and white world of fear and depression into a sunshine, technicolour world of energy, confidence and control. For nearly a third of a century I'd forgotten the sensation of just feeling great to be alive. (Carr, 2003, p. 15)

Not only that, but the epiphany drove a quixotic belief that Carr could also help other smokers to quit:

I'M GOING TO CURE THE WORLD OF SMOKING! 
These were the actual words that I greeted Joyce [his wife] with on my return. Her reaction disappointed me. She couldn't have looked more aghast if I had hit her on the knee with a hammer. The looks she used to give me when I was coughing and wheezing were bad enough, but this one was a quantum leap, "YOU'VE COMPLETELY GONE OFF YOUR ROCKER.” (Carr, 1995, pp. 6-7)

Carr's authority, while built upon his epiphany, is strengthened by his long experience of administering Easyway, directly in his clinics and at a distance through his self-help books. Through listening to the personal stories of smokers in person and in correspondence, reflecting in-depth upon his own experience and the diverse experiences of others, he claims an unparalleled insight into the psychology of smokers. This undergirds his claim to a distinctive, fine-grained hermeneutic understanding of the myriad motivations, feelings and impulses of nicotine addiction, a knowledge that he puts at the service of readers.

\section{The Paradox of Reason}

Within the texts, the rationality of readers provides the fulcrum for redemption from addiction. Smokers may be unable to stop smoking and profoundly misguided about why they smoke, but through Easyway every smoker is presented as possessing the innate capacity to interrogate their own smoking practices, to weigh up the revealed costs and to arrive at a self-evident course of action: to stop permanently:

Let me emphasise that anybody can find it easy to stop smoking, but first we need to establish the facts. No, I do not mean the scare facts. I know you are already aware of them. There is already enough information on the evils of smoking. If that was going 
to stop you, you would already have stopped. I mean, why do we find it difficult to stop? (Carr, 1999, p. 23)

He refutes discourses of determination beyond the immediate addiction itself - such as genetic predisposition, addictive personality or physical dependency - which deny the capability of the smoker to make unencumbered choices. Even the most recalcitrant smoker is presented as knowing, deep down, that they are 'a mug' who ultimately recognizes the irrationality of their predicament. Reason is thus the precondition to redemption, the capacity to weigh up and make a free, self-determining choice. Reason alone, however, cannot lead there; in the mind of the smoker, the sub-conscious deluding agency of nicotine addiction always limits it. As a result, willpower as the corollary of reason - the rational assertion of self-control over embodied urges - will not work. It can lead only, at best, to a dissatisfied cessation that is always provisional. In consequence, smokers must follow the Easyway method, they must be conducted to overcome their addictive state.

However, the texts also present rationality and addiction not as opposed but as a duality. Formal rationality, drawn at the level of institutions and society, is irrational. In several monologues, Carr condemns education as stifling and conformist, producing individuals for jobs that hold little meaning. Government is complacent or incompetent, the tobacco lobby driven by duplicitous self-interest, and the medical and public health establishment conceited and contemptuous:

My great mistake was in underestimating the sheer, incompetence, apathy, ignorance, ineptitude and plain stupidity of the very institutions that you would expect to be my strongest allies. Institutions that purport to care, like the BMA, ASH, QUIT, THE 
GOVERNMENT, THE CIVIL SERVICE, THE MEDIA and all their so-called experts who, far from assisting the poor smokers to get free, merely persist in giving them advice which is almost guaranteed to ensure their slavery for life! (Carr, 1995, p. 29)

In consequence, in Carr's view, individuals are condemned to live in nicotinogenic environments. Manipulative advertising and branding imbue smoking with glamour, a glamour amplified through fashion and cinema. Society, through over-regimented patterns of work and living, creates real personal strains and stresses that condition cigarettes as an illusory palliative. Profit-driven tobacco corporations and state exchequers dependent upon tobacco taxes use their power to ensure the cycle of tobacco production and consumption continues unabated. Alongside these, public health authorities and anti-smoking organizations, chronically incapable of confronting and treating the true nature of addiction, appear more interested in preserving their status as authorities than finding what works.

\section{False Paths}

Beyond addiction, the challenge of cessation also confronts the smoker from an unexpected direction - attempting to quit while not following the Easyway method. To do so, Carr claims, is extremely likely to lead to failure and exacts an emotional toll on the smoker in terms of shame, frustration and loss of self-belief. Even if the individual successfully abstains, he or she is likely to be pining for at least the occasional cigarette and thus remains at risk of succumbing once more to addiction. These false paths include:

- Rationality: Attempting to logically think one's own way out of smoking

- Willpower: Attempting to will oneself to stop smoking. 
- Reduction: Attempting to cut down to a 'few' or just the occasional cigarette

- Substitution. Attempting to sublimate one's smoking through alternatives such as nicotine therapy, food or alcohol

- Misapplication: Attempting to quit without following all the precepts of Easyway

Easyway presents these alternatives as more or less likely to fail because they do not direct the smoker to address the true essence of addiction. The problem of smoking is much deeper than physical need; it is a misapprehension that there is a lacuna within one's life that cigarettes can fill. In consequence, the two main conventional approaches advocated by medical professionals of willpower and pharmacological therapy are deemed wrongheaded. Willpower may suspend cigarette consumption but does not address the source of the addictive urges. Substituting one substance for another, particularly 'safer' nicotine replacement therapy, merely papers over the problem; it similarly suspends the consumption of cigarettes while keeping smokers within a state of addiction. In contrast, the application of Easyway deals fundamentally with the perverted economy of desire experienced by smokers. It reveals the need for cigarettes is nothing but an illusion.

\section{Achieving Redemption}

Once readers have been led towards understanding the costs of smoking, the delusions that they employ to justify smoking and the folly of pursuing false paths, they are now open to redemption - the final declared destination of becoming 'a happy non-smoker':

The beautiful truth is: IT IS EASY TO STOP SMOKING. It is only the indecision and moping about it that makes it difficult. Even while they are addicted to nicotine, smokers can go for relatively long periods at certain times in their lives without 
bothering about it. [...] Therefore the key to making it easy is to make stopping certain and final. Not to hope but to know you have kicked it, having made the decision. Never to doubt or question it. In fact, just the reverse - always to rejoice about it. (Carr, 1999, p. 85)

Redemption is characterized as a distinctively hopeful state: that at the moment the final cigarette is extinguished one becomes a non-smoker; that one can successfully remain a nonsmoker; that no matter the depth of one's smoking addiction, anyone can do it; that one can not only find it easy to quit but enjoyable; and that stopping smoking will lead to significant benefits with respect not only to one's health but also one's wider vitality. Easyway, in consequence, is not just about stopping smoking; it posits proper cessation as a transformatory life experience that boosts one's entire quality of life and sense of empowerment.

Once readers are assumed to have absorbed the true meaning of nicotine addiction, the point of redemption is presented as a set of instructions and a personal epiphany. The instructions are a set of summary principles that the individual is to follow. Simply expressed, the instructions are to promise never to smoke again, never to doubt one's decision, and to revel in the fact that one is no longer a smoker. Here, hope becomes joy, the moment marked by a ceremonial injunction to smoke a final cigarette. However, as well as a set of principles or rules to follow, Carr also declares that the smoker will likely experience a moment of personal revelation that is an echo of the author's own original epiphany. After some short but indeterminate period - immediately, within a few days or up to two weeks - the smoker is told to expect a moment of existential clarity whereby they will realize that they are no longer a smoker, have not even thought about smoking, and so feel free of addiction. 


\section{Discussion}

In his analysis of therapeutic self-help texts as modalities of government, Rimke (2000) argues that they offer a hyper-individualized, illusory image of self-mastery and personal growth bound to a distant authorial expertise. Individuals, through intense self-scrutiny and self-evaluation, are encouraged to work on and enhance their freedom under the guidance of these experts, to become autonomous and self-directed in ways that connect them to wider neoliberal ideals of personal responsibility. We can certainly see much of this at play in Easyway. It is a form of government for smoking cessation characterized by a guiding authority and self-interrogating subjects encountering each other at a distance through the medium of a commodified self-help text. The individual reader, in consuming the text, serves as both the responsible agent of smoking cessation and the site of a desired personal transformation away from addiction. In doing so, they express a wider obligation to take responsibility for the self - adopting a longer-term perspective, minimizing undesirable health risks through careful choices and idealizing the goals of healthier living - that accord with the objectives of contemporary public health governance (Petersen and Lupton, 1996; Petersen, 1997).

There is, however, a tension here. As I have discussed, Easyway constitutes the problem of smoking behaviour as addiction, an addiction not rooted in the potency of substance, deficient will or the configuration of neural pathways but in a personal emotional economy distorted by malign cultural deceptions (cf. Dolby, 2005, pp. 66-8). Smokers cannot trust what they think they know: about themselves, their smoking practices and addiction more widely; but neither can they trust the efficacy of public health interventions. The imperative, then, is to embrace the method in order to turn the light of reason on to the irrationality of the 
self, the erroneous beliefs prevalent in wider culture and the obfuscating practices of public health experts and institutions. In learning how to stop smoking, one must unlearn everything that one has come to believe about smoking, addiction and cessation, including what one has been told by other ostensibly reputable authorities.

In the practice of cessation, Easyway cautions self-discipline whereby new non-smokers must exercise their will not to smoke, must recognise moments of weakness and purposefully reject temptation within the uncertain terrain of everyday life (see for example Segan et al., 2008). However, self-discipline, willpower or strategies of pre-commitment (cf. Elster, 2000, pp. 66-77) are not what are conceived to be at stake in effective cessation. Rather, cessation is presented as a chosen but singularly guided resolve to see through the pervasive cultural narratives underlying smoking that constitute the inauthentic nature of one's addicted self. Smokers are not required to exert will over the self as the driving need for nicotine is not ontologically real. Rather, the intention instead must be to strip away an enculturated, illusory sense of need colonizing the self, enervating and debilitating it. Successful quitters, through a wholehearted deference to Easyway, adopt Frankfurt's (1971) formulation and make aversion to smoking what their will is to the extent that that the specious agency of addiction simply dissolves away. Failure to quit, correspondingly, can never be justified by one's personal circumstances or social situation or blamed on the inapplicability of the text; it is, rather, a consequence of one's moral blindness to the revealed truth.

One of the conclusions that Carr ultimately draws from his understanding of nicotine addiction is the generic character of addiction more widely; the physiological effects of nicotine may underpin the development of addiction but they do not define its experience. One becomes addicted because one believes - internalizing prevailing social norms and 
cultural expectations - that the substance in question cannot be relinquished without a profound personal sense of loss. The psychopharmacological properties of nicotine may be real but the driving dynamic of addiction is cultural and psychological. As a result, all addictive substances are addictive in much the same way:

All drug addiction, be it nicotine, alcohol, heroin or whatever, consists of the same basic trap. The only difference between them is the nature of the chemical used to bait the trap. All these chemicals have one thing in common: they create the illusion that they confer some crutch or benefit on their victims and, in reality, do the complete opposite. The process of finding it easy to escape from any of these traps is identical. It is to understand why and how the illusion is created, to realise that the drug does the complete opposite to the impression it gives and that addicts are not, in fact, dependent on the drug. (Carr, 1999, p. 369)

This conclusion provides an ironic counterpoint to the powerful claims within neuropsychology that all forms of addiction are, in essence, variants of a single chronic, relapsing brain disease. Underlying both Easyway and neuropsychology, in their different ontologies, epistemologies and vastly different scales of influence, are empire-building ambitions organized around monopoly claims to know and intervene in a salient social problem as it is politically conceived (cf. Courtwright, 2010).

With the Easyway method, what underlies Allen Carr's power to govern readers? What authority does he claim to write the self-help books examined here? In contrast to conventional public health cessation programmes, he makes no claims to formal expertise based on scientific education or credentialed training. He is not a doctor, researcher, or 
qualified therapist; in general, he is dismissive of these kinds of experts. Nevertheless, he claims an autodidact expertise on cigarette addiction deriving from his own experience as a smoker, his years of work in ministering Easyway at his clinics, and his ongoing, deep reflections on the psychology of smoking. Yet, none of this would be possible without charisma, his claim to extraordinary powers (Weber, 1948, see also Adair-Toteff, 2005). In the analysis, I noted how Carr recounts a mysterious epiphany whereby, at some deep level, he suddenly came to comprehend the true nature of smoking as addiction. On attaining this recognition, he quit smoking immediately without anxiety or doubt; on the contrary, he found it pleasurable and felt transformed. His Damascene conversion also bequeathed him a providential sense of his own life leading up to this moment and a missionary zeal to secure the redemption of other smokers (cf. Dolby, 2005, pp. 48-51).

Many self-help books promise unlikely miracles while their authors present preternatural personal qualities or experiences that mark them out as distinct charismatic authorities (Hendriks, 2017, p. 362, Simmonds, 1992, p. 120). Similarly, through Easyway, Carr offers plainly the substance of what his rare powers can deliver. He can redeem smokers to achieve a culturally validated ambition - to escape smoking addiction - in a way that is contrary to both medical and lay expectation - easily, pleasurably, with neither withdrawal nor the need for willpower. This promise is not grounded in formal expertise about smoking or rational knowledge concerning therapeutic application; rather, it is rooted in a deeply personal experience of suffering and an apparently unique, serendipitous transcendence of that suffering. The charismatic origins of Easyway offer something miraculous which stands in contrast to conventional - both scientific and everyday - conceptualizations of smoking addiction. 
Success, Weber's key benchmark for charisma's endurance (Turner, 2003, pp.14-16), may or may not be encountered by readers themselves. However, it is nonetheless visible through celebrity testimony, supportive journalistic accounts, a roster of blue-chip corporate clients and positive reader feedback (Easyway, 2017, cf. Joosse, 2014). Carr's own media celebrity as the stop-smoking guru burnished this charisma with regular appearances on televised talk shows and investigative reports on smoking. After his death, obituaries in The Times, The Telegraph, The Economist and elsewhere consecrated his identity as a unique anti-smoking British public hero (cf. Fowler, 2004). Meanwhile, over thirteen years since his death, the global Easyway conglomerate itself continues to brand its operations formally as Allen Carr's Easyway; similarly, counsellors trained in the method receive formal credentials as MAACTI - Member of the Association of Allen Carr Therapists International. This represents an interesting illustration of the trajectory faced by an institution in attempting to rationalize or

routinize the original leader's animating 'gifts of grace' (Weber, 2012, pp. 363-373). Despite its global growth and development, Easyway does not yet exist independently of the personality of its dead creator.

\section{Conclusion}

In her historical survey of treatments for alcoholism, Valverde (1997) argues that they face a fundamental paradox: They profess the impaired will of the addict and yet depend on a marshalling of that will in treatment to cure addiction. As a method of smoking cessation, what makes Easyway interesting is it explicitly presents an emphasis on willpower, the capacity of subjects to govern the unruly self, as mistaken. On the contrary, it offers redemption from addiction only by way of an alignment of the self with the revelation of addiction's true essence - inauthenticity. If achieved, willpower becomes irrelevant; the reasons to smoke disappear, as does the desire. 
Addiction is not a stable concept. Under particular conditions of power/knowledge, experts explain addiction by drawing particular lines of connection and causality between substances, subjectivities, bodies, places and feelings. Dominant biomedical accounts explain smoking as nicotine addiction, a chronic relapsing brain disease whereby nicotine's effects on neurochemical brain processes, along with genetic inheritance and routinized environmental triggers, produce behaviour-compelling physical cravings. The constitution of addiction under Easyway has points of connection with this orthodox account. Indeed, Carr's discovery of addiction in the early 1980s as the central problem of smoking cessation was, as we saw earlier, mirrored in medicine and public health. However, the substance of its meaning diverges. Easyway constructs addiction as a slight, recurring physical craving for nicotine in the body upon which a sweeping psycho-cultural edifice of self-deception and fear is built. It is not compromised will or the potency of nicotine that sustains addiction but the universally distorted emotional economy of smokers who have internalized the baleful effects of civilization.

However, we cannot see this as a straightforward distinction between formal and lay expertise about addiction and how to overcome it (cf. Wynne, 1996). There are, for example, clear contrasts between Easyway and the 12 Step model of Alcoholics Anonymous. To crudely reduce these: Easyway posits addiction as a culturally inculcated condition, not a fixed state of being intrinsic to the individual; furthermore, it holds that addiction must be overcome through a process of psychological and behavioural transformation rather than contained in its effects within the context of mutual endeavour. In fact, in one chapter of The Only Way to Stop Smoking Permanently (1995), Allen Carr feels compelled to dissect at length what he sees as the failure of his vastly more prominent treatment rival, the AA model, 
both to understand the true nature of addiction and to propose the most effective course of action to counteract it.

Only by understanding how addiction is produced through Easyway can we make sense of it as a particular form of self-help for addiction. Through the text, readers as active, reasoning subjects are enjoined morally to reflect upon the posited reality of the addicted self: The visceral suffering and disgust, the worldly invasion of a self-sufficient embodiment and the self's unwitting complicity through false rationalizations and evasions. Governing cessation involves a mutual positioning of author and reader. The author's guidance is rooted in a unique claim to charisma drawn from both his sufferance and mysterious transcendence of addiction. Smokers, in turn, possess reason; they can understand and learn how to stop just as the author has; however, the unconscious operation of addiction means they cannot do this alone. Furthermore, the misrecognition of nicotine addiction by other authorities, and by culture more widely, condemns other cessation strategies as not only futile but also counterproductive.

In rejecting the traditional liberal narrative of will, effort and resolve, Easyway presents a tobacco cessation solution imbued with wider meaning which, itself, is infused with the author's projection of charisma. Easyway offers something different from the tactics of selfdiscipline, pharmacological management of physical craving or non-judgemental counselling support that characterize conventional public health cessation programmes. It promises an egalitarian assurance of taking control rather than being treated, an emancipatory vision of self-discovery and personal freedom rather than cravings and coping, and a promise of a newfound vitality in the here and now rather than an abstract diminished risk of future illhealth. In short, it pledges an unconstrained and entirely solipsistic self-fashioning where the 
perfected, happy non-smoking self may be easily and pleasurably attained - but only at the cost of an unquestioning dedication and unwavering belief in the method. 


\section{References}

Acker, C. (2002). Creating the American junkie. Baltimore: Johns Hopkins University Press. Adair-Toteff, C. (2005) Max Weber's charisma. Journal of Classical Sociology, 5(2): 189204.

ASH Scotland (2013). Fast facts: nicotine is as addictive as heroin. Retrieved June 28, 2018, from https://www.ashscotland.org.uk/media/5861/4addiction.pdf

Bauman, Z. (2000). Liquid modernity. Cambridge: Polity.

Benowitz, N. (2010). Nicotine addiction. New England Journal of Medicine, 362(24): 22952303.

Berridge, V. (2007). Marketing health: Smoking and the discourse of public health in Britain, 1945-2000. Oxford: Oxford University Press.

Berridge, V. (2013). Demons: Our changing attitude to alcohol, tobacco and drugs. Oxford: Oxford University Press.

Brand, A.M. (2007). The cigarette century: The rise, fall, and deadly persistence of the product that defined America. New York: Basic.

Brose, L., McEwen, A. and West, R. (2012). Does it matter who you see to help you stop smoking? Short-term quit rates across specialist stop smoking practitioners in England. Addiction, 107(11): 2029-2036.

Bryman, A. (2016). Social research methods (5 ${ }^{\text {th }}$ ed.). Oxford: Oxford University Press.

Burnham, J. (1993). Bad habits. New York: New York University Press.

Campbell, N. (2010). Toward a critical neuroscience of addiction. BioSocieties, 5(1): 89-104.

Carr, A. (2004). Packing it in the Easyway. London: Penguin.

Carr, A. (2003) The easy way for women to stop smoking without gaining weight. London: Arcturus.

Carr, A. (1999) The Easyway to stop smoking (2 ${ }^{\text {nd }}$ ed.). London: Penguin.

Carr, A. (1995) The only way to stop smoking permanently. London: Penguin.

Cherry, S. (2008). The ontology of a self-help book: a paradox of its own existence. Social Semiotics, 18(3): 337-48.

Cohen, P. (2000). Is the addiction doctor the voodoo priest of western man? Addiction Research, 8(6): 589-98. 
Coonfield, G. (2008). Mapping addicted subjection: Towards a cartography of the addiction epidemic. Cultural Studies, 22(1): 80-113.

Courtwright, D. (2010). The NIDA brain disease paradigm: History, resistance and spinoffs. BioSocieties, 5(1): 137-147.

Denscombe, M. (2010). The affect heuristic and perceptions of 'the young smoker' as a risk object. Health, Risk \& Society, 12(5): 425-40.

Dingel, M.J., Karkazis, K., and Koenig, B.A. (2012). Framing nicotine addiction as a 'disease of the brain': Social and ethical consequences. Social Science Quarterly, 92(5): 1363-88.

Dolby, S. (2005). Self-help books: Why Americans keep reading them. Urbana: University of Illinois Press.

Duff, C. (2015). Governing drug use otherwise: For an ethics of care. Journal of Sociology, 51(1): 81-96.

Easyway (2017). About Allen Carr's Easyway. Retrieved October 31, 2017, from https://www.allencarr.com/about-allen-carrs-easyway/

Elam, M. (2015). How the brain disease paradigm remoralizes addictive behaviour. Science as Culture, 24(1): 46-64.

Elster, J. (2000) Ulysses unbound: Studies in rationality, precommitment, and constraints. Cambridge: Cambridge University Press.

Ford, H. (1914). The case against the little white slaver. Detroit: Henry Ford.

Fowler, B. (2004). Mapping the obituary: Notes towards a Bourdieusian interpretation. Sociological Review, 52(2): 148-71.

Frankfurt, H. (1971). Freedom of the will and the concept of a person. Journal of Philosophy, 68(1): 5-20.

Fraser, S., Moore, D. and Keane, H. (2014). Habits: Remaking addiction. Basingstoke: Palgrave.

Giddens, A. (1991). Modernity and self-identity: Self and society in the late modern age. Cambridge: Polity.

Goodman, J. (1992). Tobacco in history: The culture of dependence. London: Routledge.

Hammer, R., Dingel, M., Ostergren, J., Partridge, B., McCormick, J., and Koenig, B. (2013). Addiction: current criticisms of the brain disease paradigm, AJOB Neuroscience, 4(3): 27-32.

Hazleden, R. (2003). Love yourself: the relationship of the self with itself in popular self-help texts. Journal of Sociology, 39(4): 413-28. 
Hendriks, E. (2017). Breaking away from charisma? The celebrity industry's contradictory connection to charismatic authority. Communication Theory, 27(4): 347-366.

Hilton, M. (2000). Smoking in British popular culture 1800-2000. Manchester: Manchester University Press.

Hughes, J. (2003). Learning to smoke: Tobacco use in the West. Chicago: University of Chicago Press.

Illouz, Eva (2008). Saving the modern soul: Therapy, emotions, and the culture of self-help. Berkeley: University of California Press.

Joosse, P. (2014). Becoming a God: Max Weber and the social construction of charisma. Journal of Classical Sociology, 14(3): 266-83.

Keane, H. (2002). What's wrong with addiction? Carlton South: Melbourne University Press.

Keogan, S., Li, S., and Clancy, L. (2018). Allen Carr's Easyway to Stop Smoking - A randomised clinical trial. Tobacco Control, 0: 1-6. Advance access. Retrieved February 8, 2019, from

https://tobaccocontrol.bmj.com/content/tobaccocontrol/early/2018/10/25/tobaccocontrol2018-054243.full.pdf

Leith, W. (2006). Obituary: Allen Carr - Anti-smoking guru who made a fortune helping millions of people break the habit of a lifetime. Guardian. Retrieved November 21, 2018, from https://www.theguardian.com/news/2006/dec/01/guardianobituaries.smoking

McGee, M. (2005). Self-help, Inc.: Makeover culture in American life. Oxford: Oxford University Press.

McCoy, K. (2010). Into the cracks: A geology of encounters with addiction as disease and moral failing. International Journal of Qualitative Studies in Education, 23(5): 615-34.

McKenna, P. (2007) Quit smoking today without gaining weight. London: Bantham.

Morphett, K., Carter, A., Hall, W., and Gartner, C. (2017). Framing tobacco dependence as a brain disease: implications for policy and practice. Nicotine \& Tobacco Research, 19(7): 77480 .

NIDA (2018) Tobacco, nicotine, and e-cigarettes. National Institute on Drug Abuse. Retrieved June 28, 2018 from https://d14rmgtrwzf5a.cloudfront.net/sites/default/files/1344tobacco-nicotine-and-e-cigarettes_0.pdf

Nachtigal, A. and Kidron, C. (2015). Existential multiplicity and the late-modern smoker: negotiating multiple identities in a support group for smoking cessation. Sociology of Health \& Illness, 37(3): 452-67.

O'Malley, P. and Valverde, M. (2004). Pleasure, freedom and drugs: the uses of 'pleasure' in liberal governance of drug and alcohol consumption. Sociology, 38(1): 25-42. 
Pemberton, M. (2015) Stop smoking with CBT: The most powerful way to beat your addiction. London: Vermillion.

Petersen, A., and Lupton, D. (1996). The new public health: Health and self in the age of risk. London: Sage.

Petersen, A. (1997) Risk, governance and the new public health. In A. Peterson \& R. Bunton (Eds.) Foucault, Health and Medicine. Abington: Routledge.

Reinarman, C. (2005). Addiction as accomplishment: the discursive construction of disease. Addiction Research \& Theory, 13(4): 307-20.

Reith, G. (2004). Consumption and its discontents: addiction, identity and the problems of freedom. British Journal of Sociology, 55(2): 283-300.

Reith, G. (2019) Addictive consumption: Capitalism, modernity and excess. Abington: Routledge.

Rimke, H.M. (2000). Governing citizens through self-help literature. Cultural Studies, 14(1): 61-78.

Rooke, C. (2013). Harm reduction and the medicalisation of tobacco use. Sociology of Health \& Illness, 35(3): 361-76.

Room, R. (2003). The culture framing of addiction. Janus Head, 6(2): 221-34.

Rose, N. (1996). Inventing our selves: Psychology, power and personhood. Cambridge: Cambridge University Press.

Rose, N. (1999). Governing the soul, $2^{\text {nd }}$ ed. London: Free Association.

Rose, N. (2003). Neurochemical selves. Society, 41(1): 46-59.

Seal, A. (2016). Thematic analysis. In N. Gilbert \& P. Stoneman (Eds.), Researching social life, $4^{\text {th }}$ ed. London: Sage.

Sedgwick, E.K. (1992). Epidemics of the will. In J. Crary \& S. Kwinter (Eds.), Incorporations: Zone 6. New York: Urzone.

Segan, C.J., Borland, R., Hannan, A., and Stillman, S. (2008). The challenge of embracing a smoke-free lifestyle: A neglected area in smoking cessation programs. Health Education Research, 23(1): 1-9.

Simmonds, W. (1992). Women and self-help culture: reading between the lines. New Brunswick, NJ: Rutgers University Press.

Slovic, P. (2001) Cigarette smokers: rational actors or rational fools? In P. Slovic (Ed.), Smoking: Risk, perception and policy. Thousand Oaks, CA: Sage. 
Tate, C. (1999) Cigarette wars: The triumph of the little white slaver. New York: Oxford University Press.

Themelis, S. (2008) Meritocracy through education and social mobility in post-war Britain: a critical examination. British Journal of Sociology of Education, 29(5): 427-438.

Triandafilidis, Z., Ussher, J., Perz, J., and Huppatz, K. (2018). Young Australian women's accounts of smoking and quitting: a qualitative study using visual methods. BMC Women's Health, 18(5): 1-14.

Turner, S. (2003). Charisma reconsidered. Journal of Classical Sociology, 3(1): 5-26.

Valverde, M. (1997) Slavery from within: the invention of alcoholism and the question of free will. Social History, 22(3): 251-68.

Valverde, M. (1996). 'Despotism' and ethical liberal governance. Economy \& Society, 25(3): 357-372.

Valverde, M. and White-Mair, K. (1999). 'One day at a time' and other slogans for everyday life: the ethical practices of alcoholics anonymous. Sociology. 33(2): 393-410.

Weber, M. (1947). The theory of social and economic organization. New York: Oxford University Press.

Weber, M. (1948). From Max Weber: Essays in sociology. London: Routledge.

Weinberg, D. (2002). On the embodiment of addiction. Body \& Society, 8(4): 1-19.

Weinberg, D. (2013). Post-humanism, addiction and the loss of self-control: reflections on the missing core in addiction science. International Journal of Drug Policy, 24(3): 173-81.

Winkler, M., Weyers, P., Mucha, R., Stippekohl, B., Stark, R., and Pauli, P. (2011). Conditioned cues for smoking elicit preparatory responses in healthy smokers. Psychopharmacology, 213(4): 781-89.

Wynne, B. (1996). May the sheep safely graze? A reflexive view of the expert-lay knowledge divide. In S. Lash, B. Szerszynski, \& B. Wynne (Eds.) Risk, environment and modernity: Towards a new ecology. London: Sage.

\section{Author Biography}

Donncha Marron is Lecturer in Sociology at Abertay University. His research interests include economic sociology and consumption, particularly forms of consumption understood to be risky or addictive. He is the author of Consumer Credit in the United States: A Sociological Perspective from the $19^{\text {th }}$ Century to the Present (Palgrave, 2009). 